\title{
Normativas educacionais para o ensino de teatro no Brasil e na Itália: um exercício reflexivo-comparativo
}

\author{
Educational regulation for \\ theatre's teaching in Brazil and Italy: \\ a comparative and reflexive exercise
}

Taís Ferreira $^{1}$

Marcio Paim Mariot ${ }^{2}$ 


\section{Resumo}

Este artigo é um comparativo a partir da leitura e problematização de leis e normativas curriculares para o teatro na educação básica regular no Brasil e na Itália. É parte das análises de cunho teórico documental empreendidas no âmbito do projeto de pesquisa "Teatro e educação entre Brasil e Itália: modelos, processos e formação". Propomos, portanto, um exercício comparativo-reflexivo a partir do qual pretendemos ampliar nosso horizonte de expectativas sobre a presença do ensino-aprendizagem e da formação em teatro em conjunturas educacionais diversas.

Palavras-chave: pedagogia do teatro, educação básica, normativas educacionais, Itália, Brasil

\section{Abstract}

This paper is a comparative based in reading and discussion about laws and curricular regulation for the theatre in the basic education in Brazil and Italy. This is part of theoretical and documental analysis done in the research's project "Theatre and Education between Brazil and Italy: models, process and training". We propose, then, a comparative and reflexive exercise where we intend to broaden our horizon of expectations about the learning, teaching and training in theatre at different educational contexts.

Keywords: theatre's pedagogy, basic education, educational regulation, Italy, Brazil

E-ISSN: 2358.6958

\footnotetext{
1 Professora Doutora Adjunta da Universidade Federal de Pelotas - Curso de Licenciatura em Teatro. taisferreirateatro@gmail.com

2 Professor Doutor Titular do IFSul-CAVG. marciomariot@gmail.com
} 
A Itália é um país que assiste, pelo menos desde o Renascimento, a um contínuo fluxo relacional entre teatro e educação. Do teatro como ferramenta para o ensino e o aprendizado da cultura clássica greco-romana pelos jovens que frequentavam as universidades mais antigas do mundo ocidental (Bologna e Padova) e aqueles componentes das academias renascimentais, passando pelo "teatrinho" promulgado por Don Bosco nas redes de ensino salesianas desde meados do século XIX (e que influencia até hoje muitas experiências educacionais pelo mundo, sendo inclusive responsável por cunhar o termo que no Brasil assume o tom pejorativo de "teatrinho escolar"), chegando às animações teatrais levadas a cabo por homens e mulheres de teatro engajados socialmente que tomaram escolas e centro sociais de fins dos anos 60 aos anos 80 , até um fortíssimo movimento de teatro das crianças e de teatro para crianças e jovens que contemporaneamente está em curso. Deve-se ressaltar também as atuais iniciativas pedagógicas que relacionam teatro e infância, teatro e pedagogia e teatro e formação de professores promovidas por grupos assíduos no Brasil como a Societàs Rafaello Sanzio (para citar só o mais incensado em nosso país, pois a tradição de trabalho pedagógico dos coletivos teatrais italianos é ampla, sólida e difundida de norte a sul). Destarte, são dignas de nota, de estudo e de aprofundamento as relações entre teatro e educação na Itália, quase desconhecidas no Brasil, e que têm se mostrado de extrema pertinência e relevância para se pensar o estado da arte da pedagogia do teatro em termos internacionais e interculturais.

Neste artigo propomos um exercício de caráter comparativo e reflexivo a partir da leitura de leis e normativas curriculares para o teatro na educação básica no Brasil e na Itália. O trabalho apresentado configura-se como parte das análises de cunho teórico documental empreendidas no âmbito do projeto de pesquisa "Teatro e educação entre Brasil e Itália: modelos, processos e formação" (em atividade desde 2017 junto à Universidade Federal de Pelotas e contando com a colaboração de sujeitos de pesquisa e acadêmicos italianos), do qual os autores são coordenadora e professor colaborador, respectivamente ${ }^{3}$.

Justificamos o comparativo com a Itália pois, além de ser um país com ricas experiências educacionais nas artes da cena ainda não divulgadas ou estudadas no Brasil, foi lócus de pesquisa da orientadora do grupo por alguns anos, propiciando um contato não superficial com as práticas lá empreendidas e suas histórias. Ainda que haja, via de regra, um desconhecimento sobre as ações relacionando teatro e educação na Itália, podemos destacar a relevância do trabalho pedagógico em teatro naquele país tanto no âmbito da educação básica como naquilo que se refere ao teatro social (que comumente chamamos de teatro na comunidade), como na ação cultural na formação de espectadores e de gestores. O projeto de pesquisa do qual esse trabalho é oriundo tenta abarcar essas três esferas.

Portanto, sendo impossível aprofundar a problematização de todos os âmbitos dentro dos limites de um artigo acadêmico, optamos por focar a análise nos documentos oficiais relacionados à educação regular. Algumas diretrizes educacionais públicas federais para o ensino de teatro, propostas recentemente no Brasil e na Itá-

3 O projeto contou com a participação de duas bolsistas de Iniciação Científica: Roberta Postale (CNPq, 2017 e FAPERGS, 2018) e Grazielle Bessa (BIC-UFPel, 2017), que colaboraram ativamente na sistematização e organização dos dados analisados nesse artigo. 
lia, foram estudadas a fim de obter um comparativo entre os documentos oficiais vigentes, promulgados pelos ministérios da educação dos dois países (doravante MEC para o brasileiro e MIUR para o italiano), relativos ao ensino e promoção do teatro nas escolas de educação básica.

Os documentos legislativos italianos $(2015,2016)$ acerca das atividades teatrais na escola foram comparados com a Lei de Diretrizes e Bases (1996) (doravante LDB), os Parâmetros Curriculares Nacionais $(1997,2000)$ (doravante PCNs) para o ensino de Arte e a Base Nacional Curricular Comum (2018) (doravante BNCC). Comentários iniciais sobre a Base Nacional Curricular Comum em relação aos outros documentos serão tecidos ao longo do texto, ainda que o documento definitivo que abarca a educação infantil, o ensino fundamental e o ensino médio tenha sido aprovado pelo Conselho Nacional de Educação (CNE) há poucos meses (dezembro de 2018).

Apresentamos, portanto, um recorte do estudo comparativo mais amplo que vimos empreendendo ao longo dos últimos dois anos, pontuando a prática pedagógica desses países, a partir dos âmbitos metodológico e didático apresentados pelo material analisado. Cumpre notar também que esse comparativo não se propõe a ser parte das teorias do currículo, mas problematizar os modos como as indicações de documentos oficiais dos dois países percebem e normatizam o ensino de teatro na educação básica, tanto em termos teóricos como metodológicos. Uma análise sob a luz dos estudos curriculares envolveria outras questões que não são a proposta de abordagem desse artigo.

Destarte, empreendemos um exercício comparativo-reflexivo a partir do qual pretendemos ampliar nosso horizonte de expectativas sobre a presença do ensino-aprendizagem e da formação em teatro em conjunturas educacionais diversas. Compreendemos que essa abertura ao "outro" pode tanto nos fazer valorizar as conquistas e a produtividade do que vimos propondo ao longo das últimas décadas no campo das artes da cena e da educação no Brasil, como problematizar algumas "verdades" que construímos para nós mesmos e que podem ser colocadas sob rasura, revistas e possivelmente redimensionadas no momento histórico atual da educação brasileira.

\section{Contextualizando teatro e educação no Brasil e na Itália}

Partamos, então, para o diálogo com nosso "outro", nesse caso um país europeu com matriz didático-pedagógica sólida (recém alvo de uma reforma educacional, também essa proposta por gestores e não pelas bases, chamada "Buona Scuola"), calcada num modelo escolar que compreendemos como uma educação conteudista e tradicional, em termos metodológicos e didáticos.

Iniciamos o exercício analítico entre países de culturas e realidades socioeconômicas diversas dizendo que não há professores de teatro e dança com formação universitária (licenciados) voltada para tal atuando em escolas de educação básica na Itália, bem como não existem estes professores de educação básica com formação específica em artes cênicas na França ou na Espanha, entre outros países da Comunidade Europeia. 
Isso quer dizer que não há teatro e dança acontecendo nas escolas européias? Não, absolutamente. Os modos de inserção dos professores de teatro e dança na escola e suas formações docentes são presentes e bastante distintos se compararmos a esses processos formativos hoje no Brasil.

Aqui, temos cursos de licenciatura em teatro e em dança, em número cada vez maior desde as proposições da LDB (Lei de Diretrizes e Bases da Educação Nacional de $1996^{4}$ ), substituindo, portanto, as antigas licenciaturas em educação artística polivalentes. Contamos, assim, com a formação anual de profissionais capacitados, adequados aos parâmetros, normativas e leis do MEC, para ocupar os devidos espaços nas salas de aula, no ensino regular de Arte, ou na disciplina de Arte, que compreende, segundo a LDB e os PCNs (1997, 2000), as Artes Visuais, a Dança e a Música e o Teatro. A nova BNCC (2018) inclui ainda as Artes Integradas (circo, teatro de bonecos e sombras, instalações e arte da performance, animações, audiovisual, etc).

Dito isso, é importante frisar que, segundo dados do Censo Escolar do MEC de 2013, o número de professores da educação básica que atuam nas artes e que possuem formação na área é de $6 \%$ do total de docentes que atuam nessa disciplina nas escolas de educação básica do país. Destes $6 \%$, somente $3 \%$ possuem licenciatura em artes, sendo que se os números forem tomados fazendo referência às licenciaturas por linguagem específica, somente $1 \%$ têm formação específica em teatro e menos de $1 \%$ em dança. Ou seja, no amplo universo da educação básica brasileira, pouquíssimos docentes possuem formação superior na área de arte e a minoria absoluta possui formação em artes cênicas (os números totais são 505 professores com formação em teatro e 156 com formação em dança). Para um país da dimensão do Brasil, que conta com uma rede de ensino com mais de 50 milhões de estudantes e mais de 2,1 milhões de professores, estamos muito aquém ainda do necessário e do desejável ${ }^{5}$.

Em diversos países europeus, quem ensina teatro ou dança e conduz experiências com estas áreas do campo das artes nas salas de aula são ou os professores pedagogos da educação básica, docentes de outras disciplinas como língua, literatura e educação física ou os artistas parceiros das escolas, em projetos de cunho extracurricular ou de complementação de alguma disciplina do currículo. Esse sistema é chamado na França de "partenariat" (partenariado), algo mais próximo daquilo que em português conhecemos como "parceria". Parceria pedagogo-artista, artista-escola, grupo de teatro/dança-escola6.

Retomando a organização curricular das artes nas escolas europeias (Eurydice, 2009), podemos afirmar que há modalidades de inserção que podem ser classificadas como "artes integradas", ou seja, quando uma ou mais modalidades ou linguagens apresentam-se como disciplina (na Itália há, por exemplo, a disciplina de "Arte, música e imagem", que compõe o currículo obrigatório do ensino fundamental) ou

\footnotetext{
4 Lei n 9.394, de 20 de dezembro de 1996 - Lei de diretrizes e bases da educação nacional. A lei pode ser acessada na íntegra e com suas modificações no endereço eletrônico: http://www.planalto.gov.br/ccivil_03/leis//9394.htm

5 Todos esses dados referem-se ao Censo escolar da educação básica, realizado pelo Ministério da Educação em 2013. Acesso em: http://download.inep.gov. br/educacao_basica/censo_escolar/resumos_tecnicos/resumo_tecnico_censo_educacao_basica_2013.pdf

6 Essas relações foram tratadas por duas pesquisadoras no Brasil em trabalhos recentes: Maria Lucia Pupo (USP) e Mariana Oliveira (UERJ), que têm escritos de sua autoria explorando o partenariat no universo francófano.
} 
as artes em suas distintas linguagens, separadas disciplinarmente da seguinte forma (em ordem decrescente de obrigatoriedade no sistema de ensino fundamental dos 33 países pesquisados): 1) artes visuais, 2) música, 3) artesanato, 4) artes dramáticas (teatro), 5) dança, 6) artes da comunicação (cinema, audiovisual, fotografia) e 7) arquitetura.

Segundo o relatório, a metade dos países apresenta as disciplinas integradas e a outra metade as disciplinas separadas (Eurydice, 2009, p. 24). Na Itália, em particular, a música e as artes visuais são obrigatórias nos cinco primeiros anos do ensino fundamental (scuola elementare), sem especificação de carga-horária. Já nos três últimos anos do ensino fundamental (scuola superiore), a carga-horária específica mínima é de 132 horas anuais.

As disciplinas (nomeadas "linguagens" nos documentos oficiais, mas que podem ser entendidas como "componentes curriculares ou disciplinas"), desde a aprovação da LDB brasileira de 1996, são apresentadas separadamente e são quatro: artes visuais, dança, música e teatro. As artes comunicativas (fotografia e audiovisual'7) seriam componentes das artes visuais, segundo os PCNs e constituem parte das artes integradas na BNCC. A arquitetura não figura nos conteúdos escolares apresentados pelos documentos brasileiros.

O artesanato e as manifestações culturais populares (ou folclóricas) são vagamente citados ao tratar-se de arte local e relação entre arte e cultura nos PCNs, mas figuram de maneira assídua nas competências propostas em Arte propostas pela BNCC, configurando talvez o início de um outro momento no ensino das artes na educação básica no Brasil, em que as culturas tradicionais e populares e a diversidade da qual essas culturas são oriundas passem a figurar como centrais nos projetos pedagógicos, planejamentos e materiais didáticos.

Como já citado, as artes integradas fazem parte da BNCC, suscitando em alguns educadores brasileiros certa apreensão quanto a um possível retorno à polivalência nas artes, combatida pelos arte-educadores desde a década de 70 no país. No entanto, não se pode negar que a separação entre as artes é cada dia mais fugidia, ao pensarmos nos processos de hibridização e mestiçagem presentes na produção de arte contemporânea.

Até dezembro de 2017, a Arte (suas disciplinas) figura como conteúdo dos documentos de orientação curricular nacional dos níveis da educação básica (educação infantil, ensino fundamental e ensino médio), ainda que esses não se configurassem como um currículo nacional obrigatório (são parâmetros, orientações e diretrizes). No mês supracitado foi promulgada pelo MEC a BNCC, na qual as artes (divididas em artes visuais, dança, música, teatro e artes integradas) são conteúdo obrigatório dos anos iniciais aos anos finais do ensino fundamental, bem como na educação infantil. Após um ano, em dezembro de 2018, é promulgada a quarta versão do documento da BNCC, que inclui o Ensino Médio (doravante EM). Cumpre notar que houve recentemente uma reforma sofrida por esse nível de ensino, coordenada pelo Conselho

Foi no Brasil promulgada uma lei federal que dispõe sobre a obrigatoriedade da assistência a duas horas mensais de cinema nacional pelos estudantes da educação básica, mas não fica disposta nem em qual disciplina ou atividade e tampouco uma preparação de docentes e de alunos para o contato profícuo com o cinema. http://www.planalto.gov.br/ccivil_03/_Ato2011-2014/2014/Lei/L13006.htm 
Nacional de Educação (CNE), que instituiu o fim das disciplinas obrigatórias (permanecem como compulsórias nos três anos do EM somente matemática e língua portuguesa), a organização curricular por quatro áreas (o componente de Arte está contido na área de Linguagens) e a construção de percursos formativos optativos pelos jovens em pelo menos 1.200 das 3.000 horas obrigatórias para os três anos de EM.

No entanto, não há estipulação, pela lei brasileira ou pela BNCC, nem das cargas-horárias anuais e nem de quais os componentes da área de Artes obrigatórios em cada ano ou nível de ensino. Isso abre a possibilidade de diversas interpretações, tanto por parte dos gestores governamentais e escolares como em situações de caráter legal. Tão somente existe a indicação da obrigatoriedade da presença da área de Arte em diversos documentos legais do MEC (normativas educacionais, resoluções e leis) e a presença da área tanto nos PCNs, como na BNCC.

Cumpre notar que os PCNs balizaram boa parte de projetos pedagógicos tanto de escolas como de licenciaturas e cursos de formação de professores no Brasil nos últimos 20 anos e, por conseguinte, não podem ser invalidados como documentos a serem analisados e problematizados na história da arte e da educação do país, ainda que tenhamos já a BNCC em vigor e em processo de implementação nos estados e munícipios a partir de então.

\section{O teatro na educação básica regular a partir dos documentos ofi- ciais: análise comparativa}

Para fins de análise comparativa entre o ensino de teatro na escola no Brasil e na Itália foram utilizados os documentos brasileiros 1) Lei de Diretrizes e Bases da Educação/LDB (BrasiL, 1996), 2) Parâmetros Curriculares Nacionais/PCNs (BRASIL, 1997, 2000) e 3) Base Nacional Curricular Comum/BNCC (Brasil, 2018), e os italianos 1) Strategie per l'utilizzo didattico delle attività teatrali a.s. 2016/2017 "Buona Scuola" (MIUR, 2016) e 2) Teatro in classe (MIUR, 2015). A partir da análise dos documentos procedeu-se uma descrição dos pontos de aproximação e distanciamento entre as propostas dos dois países para o ensino de teatro nas escolas.

Se a LDB traz o ensino da arte como componente curricular obrigatório da educação básica no Brasil, abrangendo o teatro, as artes visuais, a dança e a música como linguagens artísticas, na Itália, os documentos do Ministero dell' Istruzione, dell' Università e della Ricerca (MIUR) apontam para o papel deste ministério na introdução do teatro na escola, através da difusão de práticas teatrais com vistas a potencializar as artes no ambiente escolar. O teatro nas escolas italianas, a partir desta proposta, deixa de ter um caráter extracurricular e se torna uma escolha didática complementar (o que difere de ser uma disciplina). No entanto, o documento italiano aponta o uso de horários extracurriculares para atingir os objetivos formativos. Cabe aqui ressaltar que as escolas italianas recebem verbas regulares para a implementação dos Planos de Ofertas Formativas (POFs), que nada mais são do que as atividades complementares ao currículo obrigatório constantes no plano trianuais de cada instituição de ensino. O teatro e dança frequentemente figuram nessa modalidade na realidade do país, de acordo com a livre escolha de cada escola e de sua respectiva gestão. 
É importante frisar que, apesar do teatro ser uma linguagem artística prevista na LDB brasileira, isto não o torna obrigatório na escola, podendo ser inserido ou não no currículo, de acordo com os projetos político-pedagógicos de estados e municípios e também de cada escola de educação básica do país, além da oferta ou falta de professores capacitados. Como na Itália as atividades com teatro nas escolas são assíduas, possivelmente mais do que no Brasil, já que também tratamos aqui de um sistema educacional que compreende números muito inferiores àqueles brasileiros ${ }^{8}$, nota-se um potencial maior para curricularização desta linguagem artística naquele país, pensando no atual contexto brasileiro para o ensino das artes.

No que se refere à formação de docentes para atuar no ensino de artes, a LDB prevê que esta deverá se dar por meio de cursos de licenciatura plena. O que se observa, entretanto, em diversas realidades nas escolas brasileiras, são professores não habilitados praticando a docência nas linguagens artísticas previstas em lei ${ }^{9}$. Já na Itália, os documentos analisados citam um projeto formativo para docentes habilitados em educação para trabalharem com teatro na escola, sendo que esse ainda não se efetivou na prática. Neste processo de formação as entidades parceiras (grupos de teatro, artistas, fundações teatrais, etc.) dispõem, além de suas competências teatrais - as quais são utilizadas nas ações extracurriculares com teatro na escola -, cursos de aperfeiçoamento para docentes.

Com relação à estrutura física para o ensino de teatro, os PCNs para o ensino fundamental atribuem à escola a competência para oferecer um espaço adequado, livre e flexível, de maneira a potencializar o processo criativo da criança. Nota-se que efetivamente, nesses mais de vinte anos que separam a promulgação dos documentos e os dias atuais, são poucas escolas que possuem esse espaço para as práticas teatrais, sendo na maioria dos casos utilizada a própria sala de aula ou outros espaços adaptados pelos professores.

Por outro lado, os documentos italianos balizadores para o ensino de teatro nas escolas apontam que os processos criativos necessitam ocorrer em "laboratórios teatrais", os quais são estruturados de forma diferenciada do que a sala de aula, com o intuito de desafiar os alunos a criarem. Ainda que algumas escolas possam ter problemas com a estrutura espacial, isso não pode impedir a atividade; as atividades podem acontecer em espaços adaptados, ou seja, sem necessidade de ser em local tradicionalmente usado para o teatro. O que faz um laboratório teatral no contexto italiano é a forma como se vive a atmosfera desse ambiente. $O$ espaço deve ser criado prioritariamente a partir das atividades dos alunos; assim, será desenvolvido neles o potencial para o fazer artístico. A única aproximação entre os dois países neste aspecto é a orientação para que seja disponibilizado um espaço adequado onde o aluno esteja confortável para o jogo teatral e os processos criativos nas artes da cena.

Uma análise comparativa da práxis pedagógica e dos conteúdos no ensino de teatro no Brasil e na Itália traz à baila reflexões oportunas para uma análise crítica da

\footnotetext{
8 Segundo dados fornecidos pelo MIUR (2017, acesso pelo sítio https://www.orizzontescuola.it/wp-content/uploads/2017/09/Dati-Avvio-anno-scolastico-2017-2018.pdf ), o número de estudantes na Itália no ano escolástico de 2017/2018 é de 7.757.849.

9 A dissertação de mestrado de Paola Oppitz, intitulada "Aula de arte sem professor de arte", defendida pelo ProfArtes UDESC em 2018, vai desvendar e problematizar alguns dos meandros desta realidade na rede estadual de ensino do Rio Grande do Sul.
} 
nossa realidade no campo do ensino das artes. Os PCNs para o ensino fundamental trazem como eixo norteador os princípios de Piaget (relação do teatro com os jogos simbólicos da criança e evolução para os jogos de regras) como uma das bases para a escrita do documento, bem como para fundamentar a organização do trabalho docente. Já os PCNs para o ensino médio destacam a abordagem triangular do ensino das artes (trazida ao Brasil por Ana Mae Barbosa, a partir das propostas de John Dewey): produção, apreciação e contextualização.

A BNCC vai expandir os objetivos pedagógicos do teatro em termos de competências e aponta dimensões do conhecimento em Arte que devem ser levadas em consideração pelas quatro linguagens no âmbito do EF, quais sejam: 1. Criação, 2. Crítica, 3. Estesia, 4. Expressão, 5. Fruição, 6. Reflexão. Segundo nossa leitura da BNCC, além dessas dimensões, próprias do campo das artes, algumas das competências gerais apresentadas pelo documento relacionam-se diretamente com as Artes e demonstram indícios de que poderão ser plenamente desenvolvidas no que tange às aulas de teatro: a) conhecimentos socioculturais; b) curiosidade intelectual, criatividade, imaginação e investigação; c) conhecer e produzir repertórios culturais; d) comunicar-se através de diversas linguagens; e) argumentação fundamentada sobre fenômenos e situações diversas; f) cuidado de si e autoconhecimento; g) socialização, cooperação, empatia e relação com a diversidade; h) autonomia ética e valores coletivos.

Cumpre ainda notar que, se essas competências para o EM e o EF fazem parte do potencial a ser desenvolvido transversalmente pela aula de teatro, no caso da educação infantil, as artes permeiam os cinco campos de experiências propostos pela BNCC (1. O eu, o outro e o nós; 2. Corpo, gestos e movimentos; 3. Traços, sons, cores e formas; 4. Escuta, fala, pensamento e imaginação; 5 . Espaços, tempos, quantidades, relações e transformações), bem como os seis direitos de aprendizagem e desenvolvimento das crianças pequenas (1. Conviver; 2. Brincar; 3. Participar; 4. Explorar; 5. Expressar; 6. Conhecer-se).

Os documentos italianos relacionados ao ensino de teatro trazem uma abordagem mais generalista do que os brasileiros quanto ao fazer pedagógico, destacando apenas a relação da formação cultural com a evolução do indivíduo e da sociedade como um todo, de forma bem ampla. Está previsto que na Itália a aprendizagem da linguagem teatral se dá através de duas maneiras: a) recepção, trabalhando-se a pedagogia do espectador para ativar processos simbólicos da linguagem teatral; $b$ ) concepção e produção de espetáculos ou mostra de processo (alunos como produtores, que possam encenar, preparar cenografia, escrever, etc.). Essas criações devem acontecer em situação de laboratório, ou seja, num espaço que incite a produção e pesquisa e não só a recepção e armazenamento de conteúdo. As mostras integrariam escolas que desenvolvem projetos com teatro, propiciando tanto o eixo da produção como aquele da recepção. Há regiões e municípios da Itália em que as mostras de teatro estudantil são bastante tradicionais e mobilizam as comunidades escolares. Há grupos teatrais e fundações teatrais (teatros públicos municipais ou regionais) que também promovem mostras de espetáculos e processos estudantis em artes da cena.

É possível identificar que o documento brasileiro para o ensino fundamental 
se distancia do italiano por não enfatizar produções artísticas, mas ações pedagógicas que relacionem a etapa do desenvolvimento simbólico do aluno (princípios de Piaget) com o teatro. Em contrapartida, a BNCC para este nível de ensino destaca a produção artística na formação do educando, enfatizando que o processo produtivo é tão importante quanto o produto, o que vai ao encontro da realidade italiana, inclusive na referência que fazem ao protagonismo do estudante no fazer teatral.

As indicações para o ensino médio no Brasil, porém, são mais próximas às italianas em relação à produção e apreciação artística. A contextualização (teórica de cunho histórico-socio-filosófico), prevista nos PCNs do ensino médio no Brasil, dentro da proposta triangular, não aparece no documento italiano, entretanto, não significa que ela não seja trabalhada na Itália, uma vez que, como já especificado, os documentos italianos são generalistas e, além disso, sublinhamos que as disciplinas que concernem à história da arte no país, na Europa e no mundo são desenvolvidas desde os anos iniciais, seguindo seu aprofundamento nos anos finais do ensino fundamental e no ensino médio (scuola elementare di primo e secondo grado, liceu o scuola tecnica).

Em ambos os países, de maneira geral, está presente a dimensão da fruição da arte na formação cidadã do indivíduo. Entretanto, observa-se um distanciamento entre Brasil e Itália quanto à valorização das memórias afetivas individuais e do coletivo manifestadas na arte, que é destacada no documento italiano. Ou seja: constata-se um interesse maior nas questões concernentes ao patrimônio imaterial e material na matriz educacional italiana. Pensando já na BNCC (2018) brasileira para o ensino fundamental, vemos um interesse maior tanto na promoção da experiência com a diversidade cultural brasileira de diversas matrizes (indígena, africana e europeia) como da valorização do patrimônio cultural nacional material e imaterial, algo que nos PCNs deixava a desejar.

Existe uma preocupação mais acentuada com a fruição do espetáculo e da produção de arte no material proposto pelo MIUR, enquanto os documentos brasileiros apresentam um foco maior naquilo que se aprende e desenvolve em sala de aula, nos processos de ensino e de aprendizagem na escola. Outro fator de distanciamento parece ser uma valorização da diversidade cultural do ponto de vista étnico racial no Brasil (apontada pelos PCNs e explorada pela BNCC), o que não é destacado no documento italiano. No entanto, na Itália, é reafirmada não só a valorização do patrimônio cultural existente, mas a construção do patrimônio cultural para as novas gerações.

Nota-se uma proximidade entre as diretrizes dos dois países quanto ao vínculo que deve ser estimulado entre a arte e o contexto histórico, político, social. As questões relacionadas à ética, presentes no documento italiano, estão implícitas nos PCNs, quando estes orientam a relacionar a arte com a filosofia. Podemos também aqui salientar que a BNCC tende a frisar a relevância das questões éticas, de diversidade e da promoção da igualdade e do bem-estar social de todos os diferentes grupos e minorias culturais brasileiras (mulheres, negros, indígenas, idosos, crianças), calando-se, contudo, sobre questões mais fortemente vinculadas à gênero e orientação sexual. As diretrizes dos dois países mostram que existe a preocupação 
com a compreensão da linguagem, com a atribuição de significados, com o desenvolvimento de um ser humano capaz de explorar a si mesmo e observar o outro e o mundo de um modo geral.

Existe uma especificidade maior no fazer pedagógico nas diretrizes do ensino de teatro no Brasil para educação infantil e os anos iniciais do fundamental, ao contrário dos documentos para o ensino médio. A proposta italiana já é mais aberta, sem especificidades, permitindo liberdade para o fazer pedagógico em teatro, o que pode ser apontado como um distanciamento nas normativas oficiais dos ministérios da educação dos dois países.

Outro ponto de distanciamento é que no Brasil as orientações curriculares para EI, EF e EM são distintas, enquanto na Itália não existe esta separação. Um aspecto que aproxima os dois países está no foco que se dá ao aluno, no que se refere à valorização das experiências dos estudantes no processo de aprendizagem, de desenvolvimento intelectual e humano. Percebe-se um destaque no trabalho artístico vinculado a um projeto pedagógico mais amplo, para além de uma educação estética, tendo como eixo norteador uma vinculação com a proposta pedagógica de cada escola.

Além disso, tanto no Brasil quanto na Itália as diretrizes apontam para uma valorização da arte na escola para melhoria dos sujeitos e suas relações com a sociedade, a arte como promotora de processos de humanização e de socialização calcados no respeito às diferenças e na promoção da diversidade. Entretanto, os documentos italianos dão mais ênfase à produção artística - como forma de aprender o teatro em si e para se desenvolver como ser humano - que os do Brasil, mais focados nos processos educacionais. A BNCC apresenta, no entanto, ênfase maior no ensino das artes como "cuidado de si", ou seja, como meio para o desenvolvimento ético, além de estético, de cada sujeito educando.

Nos documentos italianos é destacado o incentivo à criação coletiva e o compartilhamento de saberes, o que se dá não só na escola, mas na participação em eventos culturais e nas relações com outras escolas, o que não está presente nos PCNs, entretanto, é citado na BNCC: "Os processos de criação teatral passam por situações de criação coletiva e colaborativa, por intermédio de jogos, improvisações, atuações e encenações, caracterizados pela interação entre atuantes e espectadores" (Brasil, 2018). Além disso, existe um estímulo à produção escrita e à produção visual, o que não é salientado nas diretrizes brasileiras.

Outro aspecto de distanciamento está relacionado ao destaque dado pelos documentos italianos no que se refere às relações escola-comunidade/sociedade no campo das artes teatrais. Na Itália existe uma preocupação com o reflexo das atividades teatrais das instituições de ensino para fora dos muros da escola, atingindo a comunidade à qual pertence a instituição de ensino e também outras comunidades. A nova BCNN traz a proposta de ampliação das manifestações artísticas também para fora da escola, permitindo maior aproximação com a comunidade, o que se for efetivado na prática, aproximará o Brasil da realidade italiana.

Em relação à curricularização do ensino de teatro, os documentos mostram uma aproximação entre os dois países. Nota-se uma preocupação em ambos de que o te- 
atro faça parte do plano pedagógico das instituições de ensino, entretanto, no Brasil, é proposta a interdisciplinaridade com as demais linguagens, o que não está explícito nas diretrizes italianas. Já no que se refere ao registro das atividades com teatro na escola, nota-se que na Itália eles têm como objetivo maior contribuir para melhoria do processo, através da avaliação dos erros e acertos, enquanto no Brasil o foco do registro é baseado na avaliação para identificar se os alunos adquiriram habilidades e competências na aprendizagem teatral, dentro dos objetivos da proposta curricular.

Um ponto de distanciamento entre os documentos do Brasil e da Itália é a preocupação com a qualificação de profissionais previstas nas diretrizes deste país. A ausência dessa orientação no documento brasileiro pode ser devido ao fato de que no Brasil há a licenciatura em teatro. Na Itália, como não existem licenciaturas, os documentos indicam a necessidade de projetos formativos para os professores (tanto com formação em outras áreas como para as pedagogas atuantes na educação infantil e nos anos iniciais).

Um outro aspecto relevante a ser considerado é quanto à colaboração externa nas práticas pedagógicas com teatro na escola. Na Itália esta relação colaborativa com as escolas é bem melhor estruturada, com apoio dos órgãos governamentais para o estabelecimento das parcerias, enquanto no Brasil a efetividade desta relação fica a cargo dos professores que já estão engajados nos processos artísticos dos alunos. O MIUR, para facilitar as escolas na promoção de atividades teatrais, compromete-se a assinar novos protocolos de acordo com órgãos externos, os quais desenvolverão diferentes tipos de atividades teatrais nas escolas e cursos de atualização para os professores. Destaca-se ainda que é dada liberdade às escolas para decidir os termos da colaboração. Entram aqui os POFs e outros projetos, incluindo os de partenariado.

\section{Conclusões}

Assim, concluímos que, mesmo que na Itália o teatro não faça parte dos currículos mínimos obrigatórios do ensino fundamental regular e que não haja a formação específica de professores de teatro no ensino superior (licenciatura), a presença e a promoção de atividades cênicas (tanto de criação como de recepção) é assídua, relevante e historicamente constante nos ambientes escolares, sendo executada primordialmente a partir dos Planos de Oferta Formativa (POFs) trianuais das instituições de ensino básico, promovendo as relações de partenariado entre escolas (alunos e professores) e profissionais das artes cênicas (artistas, grupos teatrais, fundações de teatro e teatros oficiais públicos). As atividades de recepção são promovidas com muito mais afinco que no Brasil e o cuidado com a formação de plateias e de espectadores parece uma constante tanto nos documentos analisados quanto na práxis educacional e de políticas publicas culturais observadas in loco.

Já no Brasil, contamos com a formação de nível superior de professores habilitados para ensinar teatro através das licenciaturas em teatro, a presença curricular do teatro dentro das linguagens obrigatórias ao ensino de arte no ensino fundamental regular e uma maior sistematização metodológica e didática da formação em teatro 
através dos documentos oficiais analisados. No entanto, penamos com a falta de estruturas adequadas e de profissionais em número suficiente para o expressivo quadro de estudantes da educação básica de norte a sul do país (mais de 50 milhões, cumpre notar). Entre outros problemas, a falta de incentivo e de políticas públicas de formação de plateias e espectadores por parte do Ministério da Cultura e do Ministério da Educação e das secretarias estaduais e municipais de educação enfraquece a possibilidade do desenvolvimento de ações profícuas no eixo concernente à recepção e à fruição teatral.

Portanto, mesmo com todos os avanços legais que a área de artes cênicas alcançou no Brasil nas últimas duas décadas, percebemos que em um país no qual o teatro ainda não faz parte oficialmente dos currículos obrigatórios, ações e atividades de formação em teatro podem ser realizadas de modo bastante efetivo e frequente nas instituições de ensino, criando pontes entre o mundo das artes cênicas e o teatro na escola, investindo na formação de plateias e de espectadores e também nos processos criativos de crianças e jovens conduzidos pela parceria entre professores e artistas e entre escolas e coletivos teatrais.

Não partindo do pressuposto da superioridade de um sistema ou modo organizacional pedagógico sobre outro, no caso dos dois países analisados, concluímos que ambas as propostas, ainda que distintas entre si, podem colaborar mutuamente para se pensar novas possibilidades em teatro na educação básica e almejar novas políticas públicas para a área. Assim, o Brasil se enriquece conhecendo o modelo italiano e a Itália também, possivelmente, se enriqueceria conhecendo as boas práticas e propostas presentes em nossos documentos e leis, embora infelizmente tenhamos que assinalar que aquilo que está promulgado nas leis, normativas e orientações curriculares não se efetiva na realidade escolar de grande parte das instituições de educação básica brasileiras. Não obstante os avanços e conquistas da área de Artes em termos legais no Brasil, a concretização e experimentação das propostas encontra-se muito aquém do desejado.

\section{Referências}

BRASIL. Secretaria de educação fundamental. Parâmetros curriculares nacionais: Arte. Brasília: MEC/SEF, 1997.

BRASIL. Secretaria de educação básica. Parâmetros Curriculares Nacionais: Ensino Médio - parte II: Linguagens, Códigos e suas Tecnologias. Brasília: MEC/SEB, 2000.

BRASIL. Ministério da Educação. Lei de Diretrizes e Bases da Educação Nacional: Lei no 9.394. Brasília, 20 de dezembro de 1996.

BRASIL. Ministério da Educação e Ministério da Cultura. Programa mais cultura nas escolas: Manual de desenvolvimento das atividades. Brasília: MEC/MinC, 2014.

BRASIL. Ministério da Educação. Base Nacional Curricular Comum. Brasília: MEC, 2018. 
EURIDYCE. L'éducation artistique et culturelle à l'école en Europe. Bruxelles: EACEA, 2009.

FERREIRA, Taís. Professores/as de teatro e dança brasileiros/as como espectadores/as. 2017. 301 f. Tese (Doutorado - Programa de Pós-graduação em Artes Cênicas, Dottorato Arti Visive, Performative, Mediali) - Universidade Federal da Bahia, Università di Bologna.

ITALIA. Ministero dell'Istruzione, dell' Università e della Ricerca. Indicazione Strategiche Per L'utilizzo Didattico Delle Attività Teatrali a.s. 2016/2017 "Buona Scuola". Roma: MIUR, 2016.

ITALIA. Ministero dell'Istruzione, dell' Università e della Ricerca. Promozione Teatro in Promozione Teatro in Classe. Roma: MIUR, 2015.

Recebido em: 13/11/2018 Aprovado em: 09/02/2019 